\title{
Common gastrointestinal symptoms and associated factors among under five children in Rural Dembiya, northwest Ethiopia: a community- based cross-sectional study
}

\author{
Zemichael Gizaw ( $\sim$ zemichael12@gmail.com ) \\ University of Gondar https://orcid.org/0000-0002-6713-1975 \\ Ayenew Addisu \\ University of Gondar \\ Destaye Guadie \\ University of Gondar
}

\section{Research article}

Keywords: Gastrointestinal symptoms, intestinal parasitic infection, environmental sanitation, under five children, rural Dembiya

Posted Date: July 1st, 2019

DOl: https://doi.org/10.21203/rs.2.10788/v1

License: (c) (1) This work is licensed under a Creative Commons Attribution 4.0 International License.

Read Full License

Version of Record: A version of this preprint was published at Environmental Health Insights on January 1st, 2020. See the published version at https://doi.org/10.1177/1178630220927361. 


\section{Abstract}

Background Gastrointestinal (GI) symptoms such as abdominal discomfort, abdominal cramp, nausea, vomiting, gas in the GI tract, or changes in bowel habits (e.g., diarrhea) are common in the community. However, these symptoms may be misinterpreted and their impact and significance misunderstood, especially in the rural communities. This study was, therefore, conducted to assess common GI symptoms among children in rural Dembiya, northwest Ethiopia. Methods A community-based crosssectional study was conducted in May 2017 among 225 randomly selected under five children. The presence of Gl symptoms among children was assessed by health professionals and mothers' report. Direct stool examination technique was used to identify parasitic infections. Bacteriological analysis of drinking water was done to determine the quality of drinking water. Food safety, environmental sanitation and hygiene condition of children were assessed using standardized observation checklists. Multivariable binary logistic regression analysis was employed to identify factors associated with GI symptoms on the basis of adjusted odds ratio (AOR) with $95 \%$ confidence interval $(\mathrm{Cl})$ and $p<0.05$. Results The current study depicted that 139 of $225(61.8 \%)$ of the children had GI symptoms. Abdominal discomfort [137 of $139(98.7 \%)$ ], abdominal cramp [125 of 139(89.9\%)] and diarrhea [118 of 139(84.9\%)] were the highest GI symptoms reported. GI symptoms were significantly associated with childhood intestinal parasitic infections $[A O R=13.69,95 \% \mathrm{Cl}=3.31,56.59)]$, unclipped and unclean finger nails $[A O R=2.28,95 \% \mathrm{Cl}=$ $(1.02,5.10)]$, inadequate living environment sanitation $[A O R=2.37,95 \% \mathrm{Cl}=(1.08,5.18)]$, unclean living houses $[\mathrm{AOR}=9.06,95 \% \mathrm{Cl}=(2.60,31.54)]$ and owning livestock $[\mathrm{AOR}=4.68,95 \% \mathrm{Cl}=(1.82,12.03)]$. Conclusion The prevalence of GI symptoms among under five children in rural Dembiya, northwest Ethiopia was found to be high. Gl symptoms were significantly associated with childhood intestinal parasitic infections, hand hygiene condition of children and sanitation condition of the living environment. Therefore, preventing intestinal parasitic infections, improving hand hygiene condition and promoting environmental sanitation will have overriding contributions to prevent symptoms among children in rural Dembiya.

\section{Background}

Gl symptoms with the possible exception of heartburn usually occur as chronic or recurrent complaints attributed to the pharynx, esophagus, stomach, biliary tract, intestines, or anorectum. Gl symptoms include abdominal discomfort, abdominal cramp, nausea, vomiting, gas in the GI tract, or changes in bowel habits (e.g., diarrhea). GI symptoms are common both in developed and developing worlds. When GI symptoms are experienced as severe, or when they impact on daily life, those afflicted often attribute the symptoms to an illness and seek medical care(1-3).

Early childhood and parental socio-demographic factors have been implicated as risk factors for the development of FGIDs. Population-based studies indicated that children from single parent households, households of lower income and less-educated families more frequently showed symptoms (4-6). Moreover, GI symptoms are also associated with hand hygiene $(7,8)$, sanitation $(\mathbf{8}-10)$ and food safety and feeding habits $(7,11,12)$. 
GI symptoms are common in the community. However, these symptoms may be misinterpreted and their impact and significance misunderstood. There is little knowledge of their prevalence(2), especially in rural communities. This study was, therefore, conducted to assess common GI symptoms among children in rural Dembiya, northwest Ethiopia.

\section{Methods}

\section{Study design and description of study settings}

A community-based cross-sectional study was conducted in May 2017 in rural Dembiya. Dembiya is one of the districts in North Gondar Zone, the Amhara National Regional State, Ethiopia. In Dembiya district, hygiene and sanitation-related communicable diseases were highly prevalent. The district health office report indicated that intestinal parasitic infections and diarrheal diseases were the top four and five prevalent diseases, which accounted 5161 (9.97\%) and 4981 (9.62\%), respectively during 2017. The population in the area had had also poor access to water, sanitation and hygiene (WASH). According to the report of the district health department, clean water and latrine coverage in the district was 26.60 and $55 \%$, respectively in 2017(13).

\section{Sample size determination and sampling procedures}

This study is part of the baseline survey for Dembiya WASH-NTD project. The project was implemented to prevent intestinal parasitic infections through improved WASH. Sample size was, therefore, determined based on the prevalence of intestinal parasitic infections using single population proportion formula with the following assumptions: $p=85.1 \%$ (prevalence of intestinal parasitic infections among children aged 6-59 months in Shesha Kebkele, Wondo Genet, Southern Ethiopia during 2010)(14), 95\% confidence interval, $5 \%$ margin of error (d), and $15 \%$ non response rate. A total of 225 children aged $6-59$ months were selected from five rural kebeles (the lowest administrative units in Ethiopia). The study subjects were selected by systematic random sampling technique.

\section{Data collection tools}

We used pretested and structured questionnaire to collect socio-demographic, hygiene and sanitation related and common Gl symptom data. Direct stool examination technique was used to identify parasitic infections in children. Children were provided a plastic stool container and asked to bring approximately $15 \mathrm{~g}$ of their own stool. A drop or drops of saline were placed on a slide. Approximately $0.05 \mathrm{~g}$ of stool specimen was placed using an applicator stick and mixed with a drop of saline and covered by cover slide. Finally, the specimen was examined under the microscope at low power ( $\times 10$ objective) and high power ( $\times 40$ objective) magnifications for the identification of intestinal parasites. Stool specimen was analyzed immediately after collection(15). Water samples were taken from individual households at point of use using sterilized sampling bottles, and the samples were transported to the central laboratory within $4 \mathrm{~h}$ with cold chain. Escherichia coli (E. coli) was used as a biological indicator for drinking water quality. 


\section{Measurement of variables}

Gl symptoms among children, the primary outcome variable of this study were defined as the presence of one or more of these symptoms: abdominal discomfort, abdominal cramp, diarrhea, nausea, vomiting, bloating and perianal itching. The presence of GI symptoms was assessed by health professionals and mothers' report. Different predictor variables like presence of intestinal parasitic infections, hand washing practice, drinking water quality, food safety, households' environmental sanitation and cleanliness of living houses were clearly explained elsewhere(16).

\section{Data analysis}

Statistical Package for Social Sciences (SPSS) version 20 was used to analyze data. Frequencies and percentages were used for most variables. Univariable binary logistic regression analysis was used to choose variables for the multivariable binary logistic regression analysis on the basis of $p$-value less than 0.2. Multivariable binary logistic regression was employed to identify factors associated with $\mathrm{GI}$ symptoms on the basis of $A O R$ with $95 \% \mathrm{Cl}$ and $p<0.05$ and to control the possible effect of confounders. Hosmer and Lemeshow test was used to check model fitness.

\section{Results}

\section{Hygiene and sanitation conditions}

A total of 225 mother-child pairs were participated in this study with $100 \%$ response rate. One hundred nineteen $(52.9 \%)$ of the children were female, and 166 (73.8\%) of them were aged between $24-59$ months. One hundred thirty-four (59.6\%) of the mothers were 30 and below years old. Majority, 180 $(80.0 \%)$ of mothers didn't attend formal education and $50(22.2 \%)$ of the households had at least one member whose education level is secondary and above.

This study found that 59 of $225(26.2 \%)$ children kept their finger nails short and clean at the time of the survey. One hundred two (45.3\%) of mothers/care givers reported that they frequently washed hands of their child after playing and defecation, and before eating. Nearly a quarter, 55(24.4\%) of mothers/care givers had good hand washing practice. The bacteriological test indicated that the quality of drinking water among $158(70.2 \%)$ households was not good. The study revealed that 118 of $225(52.4 \%)$ households practiced good food safety measures at the time of the survey. Less than half, 97 of $225(43.15)$ households had access to adequate sanitation. The vast majority, 198 of $225(88.0 \%)$ households lived in unclean quarter or house. One hundred eighty-five $(82.2 \%)$ of the households had livestock at the time of the survey (Table 1).

\section{Common intestinal parasitic infections}

In this study, 58 of $225(25.8 \%)$ children were infected with one or more intestinal parasitic infections. Of the infected children, the highest proportion, 45 (77.6\%) of them were infected by Ascaris lumbricoides(Figure 1). 


\section{Common GI symptoms}

The current study depicted that 139 of $225(61.8 \%)$ children had GI symptoms. Abdominal discomfort [137 of 139(98.7\%)], abdominal cramp [125 of 139(89.9\%)] and diarrhea [118 of 139(84.9\%)] were the highest symptoms reported (Figure 2). Of the children who reported GI symptoms, almost all of them had more than one symptom (Table 2).

\section{Factors associated with gastrointestinal symptoms}

Table 3 shows factors significantly associated with GI symptoms among under five children. Age of children, educational status of mothers/care givers, hand hygiene of children, hand washing practice of mothers/care givers, drinking water quality, food safety, households' sanitation performance, cleanliness of the house, availability of livestock, and intestinal parasitic infections were variables entered into the univariable analysis. All other variables except age of children, educational status of mothers and hand washing practice of mothers were selected for the multivariable binary logistic regression analysis.

This study found that intestinal parasitic infections were statistically associated with GI symptoms among children. The probability of GI symptoms was 13.69 times to be higher among children who had intestinal parasitic infections $(A O R=13.69,95 \% \mathrm{Cl}=3.31,56.59)$ ).

The current study identified that hygiene and sanitation conditions were significantly associated with GI symptoms. The likelihood of having GI symptoms was 2.28 times to be higher among children who didn't keep their finger nails short and clean $(A O R=2.28,95 \% \mathrm{Cl}=(1.02,5.10))$. Similarly, children with no access to adequate sanitation had higher odds to have GI symptoms compared with their counterparts $(A O R=2.37,95 \% \mathrm{Cl}=(1.08,5.18))$. The odds of having $\mathrm{Gl}$ symptoms was 9.06 times to be higher among children who lived in unclean houses $(\mathrm{AOR}=9.06,95 \% \mathrm{Cl}=(2.60,31.54))$. The likelihood of $\mathrm{Gl}$ symptoms among children was higher in households who had livestock $(A O R=4.68,95 \% \mathrm{Cl}=(1.82,12.03))$.

\section{Discussion}

This community-based cross-sectional study found that 139 of $225(61.8 \%)$ children had one or more GI symptoms. Abdominal discomfort [137 of 139(98.7\%)], abdominal cramp [125 of 139(89.9\%)] and diarrhea [118 of $139(84.9 \%)$ ] were the highest GI symptoms reported. The finding of the current study is higher than the findings of studies in Colombia (29\%) (17), Panama (28.7\%)(18), ElSalvador (20\%)(19), Ecuador (22.8\%) (20) and Italy (54.9\%)(21). The possible explanation for this difference might be due to socio-demographic, hygiene and sanitation differences.

This study showed that GI symptoms were significantly associated with intestinal parasitic infections. GI symptoms were common among children who had one or more intestinal parasitic infections. This finding is in line with the findings of other studies (22-25). It might be due to the fact that intestinal parasitic infections could trigger changes in immune function, metabolic processes, and intestinal 
microflora and result in abnormal intestinal or extraintestinal physiology that could be associated with symptoms persisting well after the infection (26-28).

The current study also identified that hand hygiene was significantly associated with GI symptoms. The likelihood of having GI symptoms was higher among children who didn't keep their finger nails short and clean. Other studies also reported the association of hand hygiene and GI symptoms among children ( 7 , $29,30)$. This might be due to the fact that a number of infectious diseases like gastrointestinal infections can be spread from one person to another by contaminated hands. Washing hands properly can help prevent the spread of the germs (like bacteria and viruses) that cause gastrointestinal infections (30-32).

This study depicted that GI symptoms among children were statistically associated with sanitation condition of the living environment. Children with no access to adequate sanitation had higher odds to have GI symptoms. The effect of poor sanitation on GI symptoms can be justified that poor sanitation (indiscriminate dumping of wastes and open urination and defecation) spreads enteric pathogens. As discussed above enteric pathogens are associated with GI symptoms (33-35).

This study revealed that GI symptoms were significantly associated with presence of livestock. The likelihood of GI symptoms among children was higher in households who own livestock. This finding is supported by the finding of another study (36). This can be justified that owning animals increases the risk of zoonotic intestinal parasitic infections and in turn associates with $\mathrm{Gl}$ symptoms $(\mathbf{3 7}, \mathbf{3 8})$.

\section{Limitation of the study}

We didn't use the Rome criteria to measure functional gastrointestinal disorders (FGDIs) while the tool is recognized as the official questionnaires for the diagnosis FGDIs.

\section{Conclusions}

The prevalence of GI symptoms among under five children in rural Dembiya, northwest Ethiopia was found to be high. GI symptoms were significantly associated with childhood intestinal parasitic infections, hand hygiene condition of children and sanitation condition of the living environment. Therefore, preventing intestinal parasitic infections, improving hand hygiene condition and promoting environmental sanitation will have overriding contributions to prevent $\mathrm{Gl}$ symptoms among children in Rural Dembiya.

\section{Abbreviations}

AOR: Adjusted Odds Ratio; Cl: Confidence Interval; COR: Crude Odds Ratio; FGDIs: Functional Gastrointestinal Disorders; GI symptoms: Gastrointestinal symptoms; IPS: Intestinal Parasitic Infections; SPSS: Statistical Package for Social Sciences; WASH: Water, Sanitation and Hygiene

\section{Declarations}




\section{Ethics approval and consent to participate}

Ethical clearance was obtained from the Institutional Review Board of the University of Gondar. Authors obtained verbal informed consent from the mothers as the study did not use risky procedure and there were no risks due to participation in this research project. The collected data were used only for this research purpose and kept with complete confidentiality. Privacy was assured during data collection. Appropriate anthelmintic drugs were given for infected children.

\section{Consent for publication}

This manuscript does not contain any individual person's data.

\section{Availability of data and material}

Data will be made available upon requesting the primary author.

\section{Competing interest}

None of the authors have any competing interests in the manuscript.

\section{Funding information}

The study was funded by NALA foundation. The funding institution had no role in study design, data collection, data analysis, data interpretation, or writing of the report. The corresponding author had full access to all the data in the study and had final responsibility for the decision to submit for publication.

\section{Authors' contribution}

All the authors actively participated during conception of the research issue, data collection, analysis and interpretation of results. ZG had designed the protocol and wrote the manuscript. AA and DG supervised the overall research process. All the authors read and approved the final manuscript.

\section{Acknowledgment}

The authors are pleased to acknowledge data collectors, field supervisors, study participants, and NALA foundation for their unreserved contributions to the success of this study.

\section{References}

1. Drossman D. The functional gastrointestinal disorders ant the Rome II process. Gut. 1999;45(2):1-5.

2. Norton J. Greenberger. Overview of GI Symptoms. Harvard Medical School. MSD manual professional version. Available at https://www.msdmanuals.com/professional/gastrointestinaldisorders/symptoms-ofgidisorders/overview-of-gi-symptoms. 
3. Hunt R, Quigley E, Abbas Z, Eliakim A, Emmanuel A, Goh K-L, et al. Coping with common gastrointestinal symptoms in the community: a global perspective on heartburn, constipation, bloating, and abdominal pain/discomfort May 2013. Journal of clinical gastroenterology. 2014;48(7):567-78.

4. Ramchandani PG, Hotopf M, Sandhu B, Stein A. The epidemiology of recurrent abdominal pain from 2 to 6 years of age: results of a large, population-based study. Pediatrics. 2005;116(1):46-50.

5. Chitkara DK, Rawat DJ, Talley NJ. The epidemiology of childhood recurrent abdominal pain in Western countries: a systematic review. The American journal of gastroenterology. 2005;100(8):1868.

6. Grøholt E-K, Stigum H, Nordhagen R, Köhler L. Recurrent pain in children, socio-economic factors and accumulation in families. European journal of epidemiology. 2003;18(10):965-75.

7. Kaindi D, Schelling E, Wangoh J, Imungi J, Farah Z, Meile L. Risk factors for symptoms of gastrointestinal illness in rural town Isiolo, Kenya. Zoonoses and public health. 2012;59(2):118-25.

8. Pickering AJ, Davis J, Walters SP, Horak HM, Keymer DP, Mushi D, et al. Hands, water, and health: fecal contamination in Tanzanian communities with improved, non-networked water supplies. Environmental science \& technology. 2010;44(9):3267-72.

9. McGregor AC, Wright SG. Gastrointestinal symptoms in travellers. Clinical Medicine. 2015;15(1):93-5.

10. López-Serrano P, Pérez-Calle JL, Pérez-Fernández MT, Fernández-Font JM, Boixeda de Miguel D, Fernández-Rodríguez CM. Environmental risk factors in inflammatory bowel diseases. Investigating the hygiene hypothesis: a Spanish case-control study. Scandinavian journal of gastroenterology. 2010;45(12):1464-71.

11. Little C, Gillespie I. Prepared salads and public health. Journal of Applied Microbiology. 2008;105(6):1729-43.

12. Bonfoh B, Wasem A, Traore A, Fane A, Spillmann H, Simbé C, et al. Microbiological quality of cows' milk taken at different intervals from the udder to the selling point in Bamako (Mali). Food control. 2003;14(7):495-500.

13. Dembiya district health office annual report 2017, by Tsigereda Kefale and others, Koladiba: officer of district health office, Amhara Region, Ethiopia, 2017.

14. Nyantekyi LA, Legesse M, Belay M, Tadesse K, Manaye K, Macias C, et al. Intestinal parasitic infections among under-five children and maternal awareness about the infections in Shesha Kekele, Wondo Genet, Southern Ethiopia. Ethiopian Journal of Health Development. 2010;24(3).

15. World Health Organization. Training manual on diagnosis of intestinal parasites based on the WHO bench aids for the diagnosis of intestinal parasites, district laboratory practice in tropical countries. WHO/CTD/SIP/98.2 CD-Rom 2004. Available at http://usaf.phsource.us/PH/PDF/HELM/trainingmanual_sip98-2.pdf. Accessed 01 Nov 2017.

16. Gizaw Z, Adane T, Azanaw J, Addisu A, Haile D. Childhood intestinal parasitic infection and sanitation predictors in rural Dembiya, northwest Ethiopia. Environmental health and preventive medicine. 2018;23(1):26. 
17. Saps M, Nichols-Vinueza DX, Rosen JM, Velasco-Benítez CA. Prevalence of functional gastrointestinal disorders in Colombian school children. The Journal of pediatrics. 2014;164(3):5425. e1.

18. Lu PL, Saps M, Chanis RA, Velasco-Benítez CA. The prevalence of functional gastrointestinal disorders in children in Panama: a school-based study. Acta Paediatrica. 2016;105(5):e232-e6.

19. Zablah R, Velasco-Benítez C, Merlos I, Bonilla S, Saps M. Prevalence of functional gastrointestinal disorders in school-aged children in El Salvador. Revista de Gastroenterología de México (English Edition). 2015;80(3):186-91.

20. Játiva E, Velasco-Benítez CA, Koppen IJ, Játiva-Cabezas Z, Saps M. Prevalence of functional gastrointestinal disorders in schoolchildren in Ecuador. Journal of pediatric gastroenterology and nutrition. 2016;63(1):25-8.

21. lacono G, Merolla R, D'Amico D, Bonci E, Cavataio F, Di Prima L, et al. Gastrointestinal symptoms in infancy: a population-based prospective study. Digestive and liver disease. 2005;37(6):432-8.

22. Blitz J, Riddle MS, Porter CK. The Risk of Chronic Gastrointestinal Disorders Following Acute Infection with Intestinal Parasites. Frontiers in microbiology. 2018;9:17.

23. Connor BA, Riddle MS. Post-infectious sequelae of travelers' diarrhea. Journal of travel medicine. 2013;20(5):303-12.

24. Futagami S, Itoh T, Sakamoto C. Systematic review with meta-analysis: post-infectious functional dyspepsia. Alimentary pharmacology \& therapeutics. 2015;41(2):177-88.

25. Schwille-Kiuntke J, Mazurak N, Enck P. Systematic review with meta-analysis: post-infectious irritable bowel syndrome after travellers' diarrhoea. Alimentary pharmacology \& therapeutics. 2015;41(11):1029-37.

26. Verdu EF, Riddle MS. Chronic gastrointestinal consequences of acute infectious diarrhea: evolving concepts in epidemiology and pathogenesis. The American journal of gastroenterology. 2012;107(7):981.

27. Deising A, Gutierrez RL, Porter CK, Riddle MS. Postinfectious functional gastrointestinal disorders: a focus on epidemiology and research agendas. Gastroenterology \& hepatology. 2013;9(3):145.

28. da Fonseca DM, Hand TW, Han S-J, Gerner MY, Zaretsky AG, Byrd AL, et al. Microbiota-dependent sequelae of acute infection compromise tissue-specific immunity. Cell. 2015;163(2):354-66.

29. Willmott M, Nicholson A, Busse H, MacArthur GJ, Brookes S, Campbell R. Effectiveness of hand hygiene interventions in reducing illness absence among children in educational settings: a systematic review and meta-analysis. Archives of disease in childhood. 2016;101(1):42-50.

30. Aiello AE, Coulborn RM, Perez V, Larson EL. Effect of hand hygiene on infectious disease risk in the community setting: a meta-analysis. American journal of public health. 2008;98(8):1372-81.

31. Mathur P. Hand hygiene: back to the basics of infection control. The Indian journal of medical research. 2011;134(5):611. 
32. Bloomfield SF, Aiello AE, Cookson B, O'boyle C, Larson EL. The effectiveness of hand hygiene procedures in reducing the risks of infections in home and community settings including handwashing and alcohol-based hand sanitizers. American Journal of Infection Control. 2007;35(10):S27-S64.

33. Mara D, Lane J, Scott B, Trouba D. Sanitation and health. PLoS medicine. 2010;7(11):e1000363.

34. Prüss-Ustün A, Bartram J, Clasen T, Colford Jr JM, Cumming O, Curtis V, et al. Burden of disease from inadequate water, sanitation and hygiene in low-and middle-income settings: a retrospective analysis of data from 145 countries. Tropical Medicine \& International Health. 2014;19(8):894-905.

35. Bartram J, Cairncross S. Hygiene, sanitation, and water: forgotten foundations of health. PLoS medicine. 2010;7(11):e1000367.

36. Heusinkveld M, Mughini-Gras L, Pijnacker R, Vennema H, Scholts R, van Huisstede-Vlaanderen K, et al. Potential causative agents of acute gastroenteritis in households with preschool children: prevalence, risk factors, clinical relevance and household transmission. European Journal of Clinical Microbiology \& Infectious Diseases. 2016;35(10):1691-700.

37. Thumbi S, Njenga MK, Marsh TL, Noh S, Otiang E, Munyua P, et al. Linking human health and livestock health: a "one-health" platform for integrated analysis of human health, livestock health, and economic welfare in livestock dependent communities. PloS one. 2015;10(3):e0120761.

38. Traub RJ, Robertson ID, Irwin P, Mencke N, Thompson RA. The prevalence, intensities and risk factors associated with geohelminth infection in tea-growing communities of Assam, India. Tropical Medicine \& International Health. 2004;9(6):688-701.

\section{Tables}

Table 1: Personal hygiene of children aged 6 - 59 months in rural Dembiya, northwest Ethiopia, May 2017. 


\section{Hygiene variables}

Children's finger nails kept short

Yes

No

Children frequently wash their hands after playing, defecation, and before eating Yes

No

Mothers' or care givers hand washing practice

Good

Not good

Drinking water quality

Good

Not good

Food safety practices

Good

Poor

Households sanitation performance

Adequate

Not adequate

Cleanliness of the living quarter or house

Good

Not good

The household have livestock

No

Yes
59

166

26.2

73.8

102

45.3

123

54.7

55

170

24.4

75.6

67

158

29.8

70.2

118

52.4

107

47.6

97

128

43.1

56.9

27

12.0

198

88.0

40

17.8

185

Table 2: Number of GI symptoms found in under five children in rural Dembiya, northwest Ethiopia, May 2017

\begin{tabular}{ccc}
\hline Number of gastrointestinal symptoms found & Frequency & Percent \\
\hline No & 86 & 38.2 \\
One & 2 & 0.9 \\
Two & 12 & 5.3 \\
Three & 25 & 11.1 \\
Four & 40 & 17.8 \\
Five & 40 & 17.8 \\
Six & 17 & 7.6 \\
Ten & 3 & 1.3 \\
\hline
\end{tabular}

Table 3: Factors with GI symptoms among under five children in rural Dembiya, northwest Ethiopia, May 2017. 


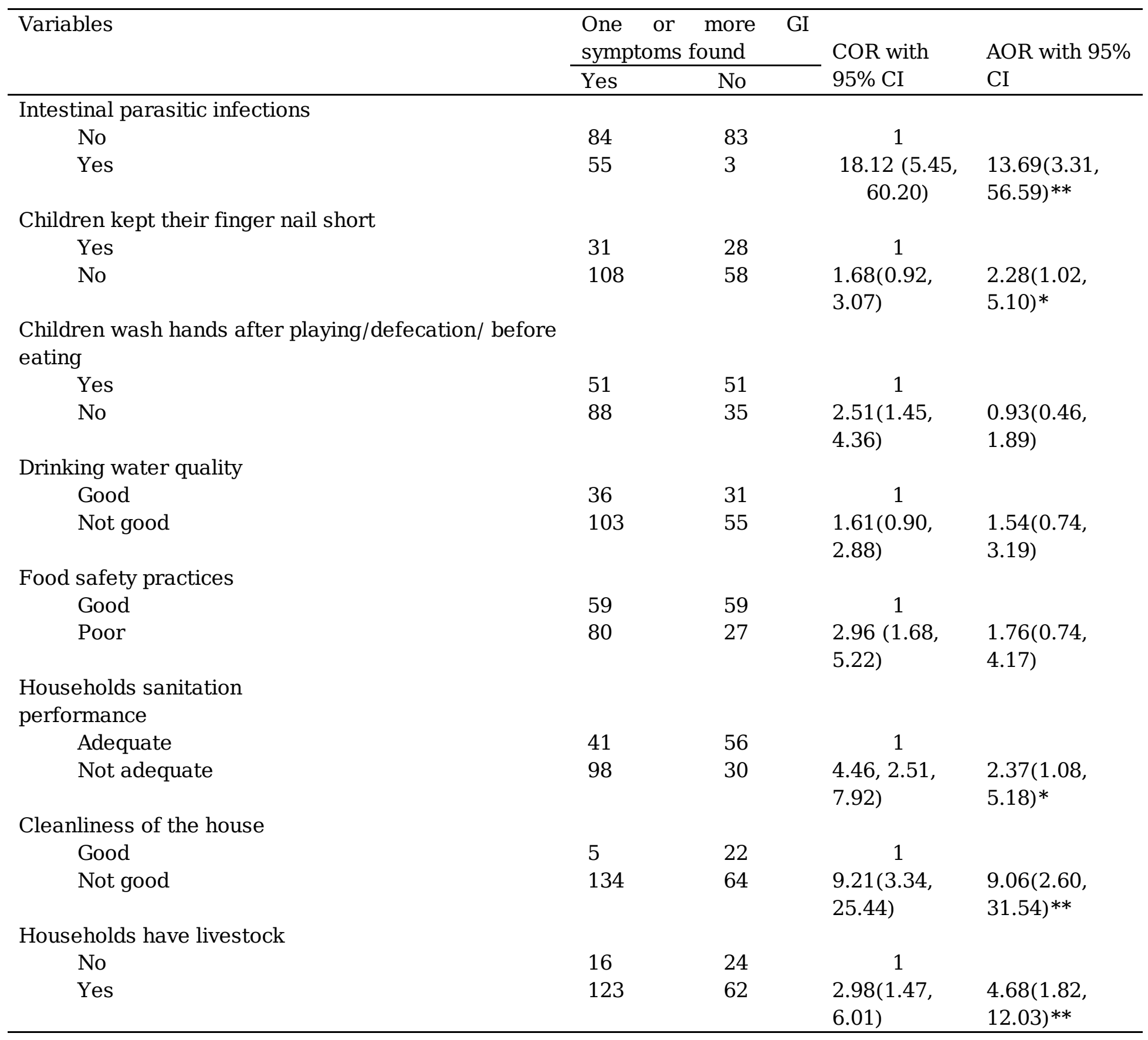

*Statistically significant at $\mathrm{p}<0.05 \mid * *$ statistically significant at $\mathrm{p}<0.001 \mid$ Hosmer and Lemeshow test $=0.335$

\section{Figures}




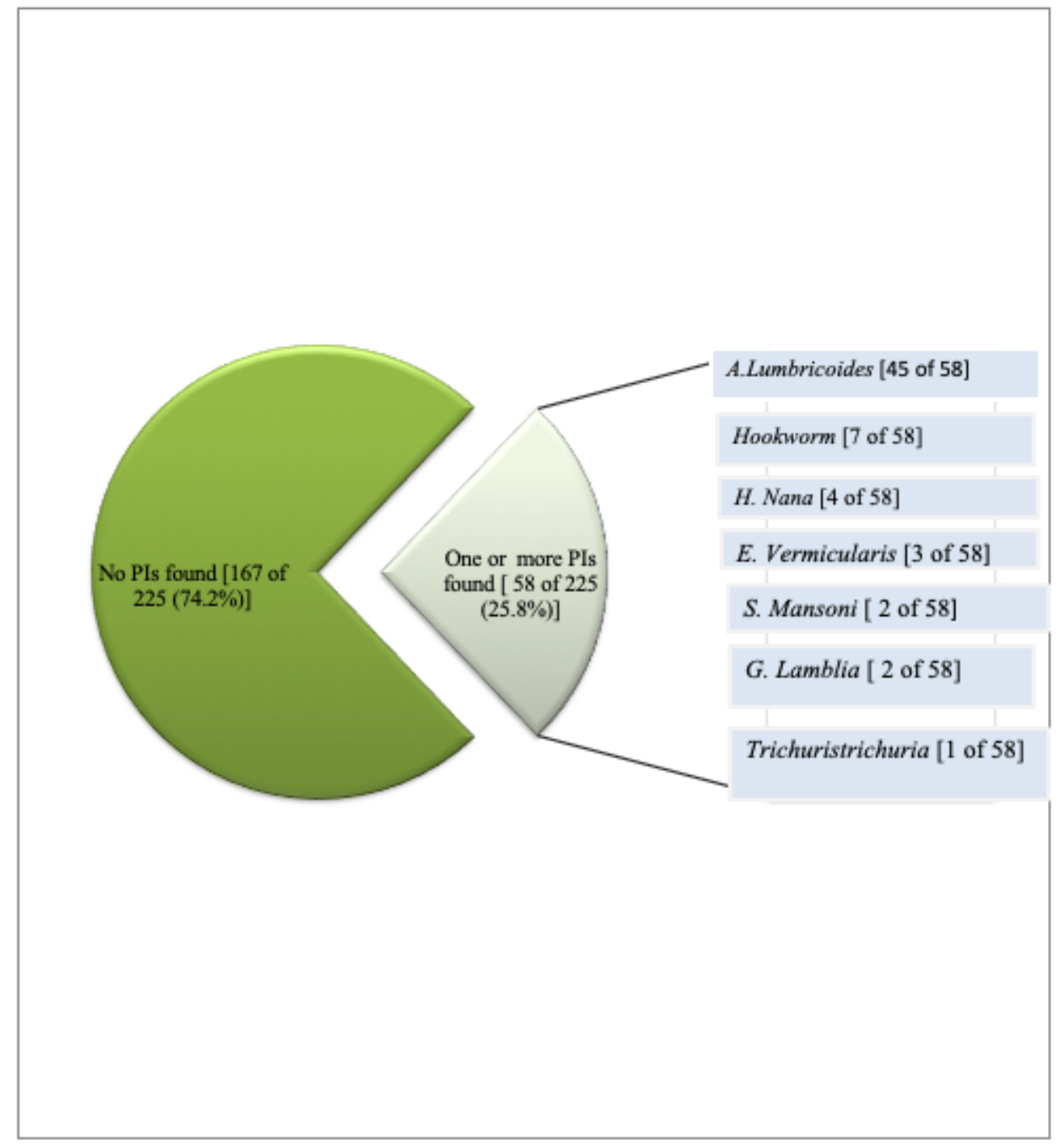

\section{Figure 1}

Prevalence and commonly identified IPs among under five children in rural Dembiya, northwest Ethiopia, May 2017 


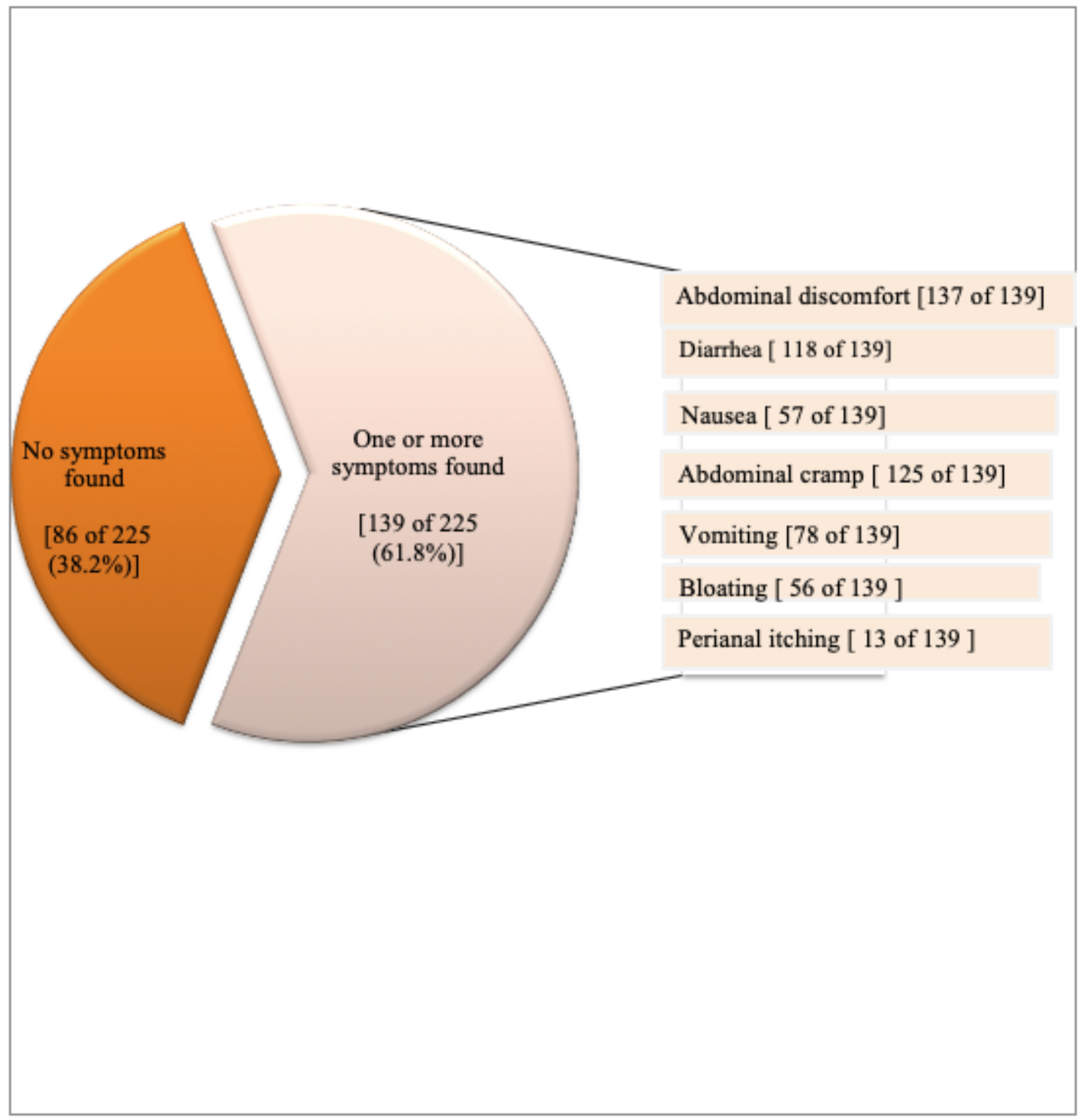

Figure 2

Prevalence and commonly identified GI symptoms among under five children in rural Dembiya, northwest Ethiopia, May 2017 